\title{
Using the Augmented Reality to Teach of Global Reading of Preschoolers with Autism Spectrum Disorders
}

\author{
Tamila H. Kolomoiets ${ }^{10000-0002-7321-0901]}$ and Darja A. Kassim² \\ ${ }^{1}$ Kryvyi Rih State Pedagogical University, 54, Gagarina Ave., Kryvyi Rih, 50086, Ukraine \\ tamilak2561@gmail.com \\ ${ }^{2}$ Kryvyi Rih Metallurgical Institute of the National Metallurgical Academy of Ukraine, \\ 5, Stephana Tilhy St., Kryvyi Rih, 50006, Ukraine
}

\begin{abstract}
Over the last decade a significant increasing of the number of children with autism spectrum disorders (ASD) in the world is marked. Ukraine is no exception. High rates of disease ASD require finding the new ways of correcting these groups of children. The aim of the research: to substantiate feasibility of using of the augmented reality's technologies to teach of global reading in a special education of autistic children. In the course of the study an experiment, descriptive and comparative analysis methods, generalization, logical research method were used. Results of the research: it is shown that, it is expedient to use technologies of the augmented reality in the educational and correctional process of children with ASD to teach them of global reading. Using the augmented reality reveals a number of new opportunities, the promising of which is an interaction with the artificial world through mobile devices, which are more accessible and predictable for the special development of autistic children. At the initial stage of teaching of global reading, the instrument of augmented reality is used in a set of successive task groups. The first of these is aimed at the development of visual perception, the formation of the ability to analyze, isolate and generalize, navigate in space. The second and third set of tasks included the teaching of children to understand the meaning of words, the correlation of words with images presented on the screen of gadgets. At the final stage, namely, teaching of global reading, the technology of augmented reality has opened unlimited possibilities for using of various text materials and virtual images to them. Conclusions: a) an analysis of experimental work with preschoolers with ASD suggests that the use of augmented reality in teaching of global reading of children helps to increase the efficiency of the educational and correctional process; b) the technology of the augmented reality has allowed rising to a qualitatively new level of mastering of global reading by autistic children; c) prospects for further experimental research will be the implementation of the proposed methodology and obtaining its effectiveness and efficiency in practice.
\end{abstract}

Keywords: children with autism spectrum disorders (ASD), preschoolers, augmented reality's technologies, global reading, correctional education. 


\section{Introduction}

A significant increase of interest of researchers, physicians, doctors, educators to the problem of autism spectrum disorders (ASD) of children has been marked over the past decade. This is due to the rapid increase in the number of children with autism from 1 to 1000 cases to $1-100$ (Dennis Ougrin, Great Britain) [3, p. 24]. The American Center for Disease Control and Prevention estimates the prevalence of autism in the United States as a single case for 88 children. Indicator of autism prevalence is steadily increasing by $29 \%$ annually. Ukraine is no exception. According to the Ministry of Health of Ukraine, the incidence of ASD from 2006 to 2015 increased by 2.5 times. Differences in numerical indicators are related to the lack of survey technologies and, according to Ihor A. Martsenkovskyi, with the late diagnosis of the disease in the country. Most cases of ASD are diagnosed at the age of 30-50 and 58-71 months [3, p. 59]. Late detection of autistic disorders negatively affects to their treatment and psychological and pedagogical correction.

As noted by Martsenkovskyi, children autistic disorders is connected with violations of neurodevelopment and they are characterized by qualitative deviations in social reciprocity, verbal and non-verbal communication, preceptor violations and stereotypical forms of behavior [3].

Symptoms of communication disorder are occurred in a delay or complete absence of spoken language, using of linguistic stamps and the lack of need for communication with outside world. The peculiarities of autistic children's speech correction, learning them for global reading are little studied. Currently, there is no scientific methodology for teaching of global reading of children with autism and poor speech.

According to the analysis of the practice of educational-rehabilitation centers, teachers teach children with ASD reading by analytical-synthetic sound-letter method, by the method of Glenn Doman and Bronislava D. Korsunskaia [1]. Multiple tasks are considered as a prerequisite for the formation of skills and abilities of reading.

Thus, there is a need to develop an experimental method of global reading's teaching of children with autism and delay of linguistic development.

A number of domestic and foreign scientists: Nadezhda S. Zhukova, Iryna P. Lohvinova, Larisa G. Nurieva, Elena M. Mastiukova, Mariia K. Sheremet engage by the researches of speech disorders, reading skills of autistic children.

\section{The Aim of the Study}

The aim of the study is to identify, select and test the teaching method for global reading using the technology of the augmented reality of preschool children with ASD, which significantly improves of the effectiveness of correctional educational processes. 


\section{Results and Discussion}

Under the augmented reality, they understand the technology of addition, the introduction of virtual information to real-life, which allows perceiving it as a part of real life [4]. If you use high-quality content, then a person is artificially formed erasing the border between the artificial world and reality. This tool causes a maximum of emotions, and also allows interacting with the investigated object [6].

Disorders of the autism spectrum are considered by scientists as a combination of total (pervasive) development, characterized by qualitative violation of communication, social interaction, limited interests and stereotypical forms of behavior. Such children do not show interest in communicating with others without understanding the motives of their behavior. Instead, they prefer to interact with mobile devices, set a close connection with them, since the result of their actions is always predictable for them. Thus, using of augmented reality technologies, as the means of learning, most closely corresponds to the peculiarities of the perception and thinking of autistic children.

The immortality of social interaction, as one of the three main domains of clinical disorders, is decisive in autistic disorders. One of the manifestations of this domain - a qualitative violation of communication - includes a delay or complete lack of speech, limited nonverbal communication, and inability to initiate and maintain a conversation. A completely different communication takes place with gadgets, during which the child there is a strong and deep emotional empathy, a sense of enthusiasm, a willingness to cooperate, and thus learn. At the initial stage of using augmented reality, the language of children with ASD is aimed at satisfying their own needs. Virtual communication contributes to the development of impulsive speech as the basis for the formation of expressive speech.

Delay of linguistic development of children with autistic disorders, as well as children with underdeveloped speech, is related to the immortality of a synthetic type of synthetic activity, which leads to a low level of formation of their abilities: to distinguish tempo-rhythmic characteristics of speech, component of the structure of words; to comprehend and memorize the text; to establish systems of relationships between words.

According to the results of Valentyna V. Tarasun's research, demerits of successive syntheses were discovered in fewer children with underdeveloped speech (US), characterized by autistic children, which caused underdevelopment of their special abilities: to reproduce a certain sequence of rhythmic sounds and melodies; to form a system of sounds, syllables; to carry out linguistic communication and the actual statement [7].

At the same time, the good visual memory of the child with ASD, the ability to perceive the graphic image of the word and correlate it with the real objects of the surrounding world create positive learning environment for global reading.

In view of the fact that in the scientific literature we have not been able to find a special method of teaching global reading of children with ASD, we have developed such a method for children from 4 to 8 years of age using the technology of augmented reality. Using of the augmented reality in the correctional educational processes reveals a number of new possibilities. The advantages of technology include [6]: 
- strong emotional responses, since the emergence of virtual objects causes children a state of admiration and surprise, which contributes children's interest and motivation for learning;

- interactivity, which contributes to better memory;

- possibilities of interaction with the artificial world by means of mobile devices, which is a significant advantage of the augmented reality to the virtual reality;

- possibility to conduct virtual classes.

Consequently, the target model of a teaching method formation of global reading using the augmented reality technology of children with autistic spectrum disorders takes the form (Fig. 1).

\section{PROBLEM: disorders of the autistic spectrum in children}

TASK: to develop and experimentally test the teaching methodology for global reading of children with autism and delay of linguistic development

GOAL: definition, development and testing of teaching methods for global reading using the augmented reality technology of preschool children with ASD

Children's Development Environment with ASD: Multidisciplinary Training and Rehabilitation Center \# 1 of Dnipropetrovsk Oblast Council

Realization of the augmented reality technology in the teaching of global reading of children with ASD (see Fig. 2).

Instruments Methods Means Information resources

RESULT: Improving the effectiveness of correctional educational processes of teaching reading of children with ASD

Fig. 1. The target model of a teaching method realization of global reading using the augmented reality technology of children with ASD 
All the work on developing formation of global reading skills of autistic children using augmented reality consisted of several stages (Fig. 2).

Initially, methods and techniques aimed to formulate simultaneous synthesis of a clear schematization of internal experience were used, which is the basis of linguistic knowledge. Another trend in educational and correctional work focused on the successive structures of synthesis of certain elements at successive rows (Valentyna V. Tarasun).
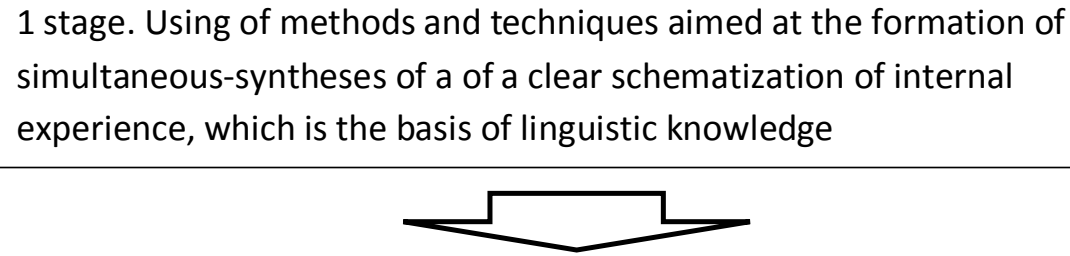

2 stage. Teaching children of understanding the meaning of words and their correlation with images, as well as the sequence of actions of the plot image

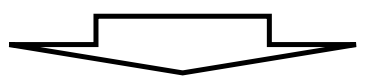

3 stage. Execution of movements and repetition of phrases according to the model of the teacher in a certain sequence

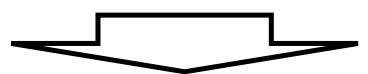

4 stage. The child's choice of the card with the corresponding image and its correlation with the word on the card

Fig. 2. Stages of the implementation of the augmented reality technology in the teaching of global reading of children with ASD

Children were offered a set of tasks for the development of simulative and successive structures. Give examples of some groups of exercises and tasks. The first group of tasks involves the development of visual perception of children, forming of the ability to analyze, isolate and generalize, navigate in space:

1. Selection of a figure from a homogeneous background (the sample of Revo d'Allon) - green objects on a green background.

2. Naming contour-depicted objects imposed on each other (figure of Walther Poppelreuter). 
3. Classification of objects according to the logical categories proposed by the teacher: a car, a table, a sweater, a pear, a cup, a skittle, socks, etc.

4. Memorization of four subject drawings offered by the teacher, followed by a search in a bunch of other pictures.

5. Finding the differences between two mirrored figures.

The augmented reality can be used as shown in Fig. 3 during performing the exercise of this group.

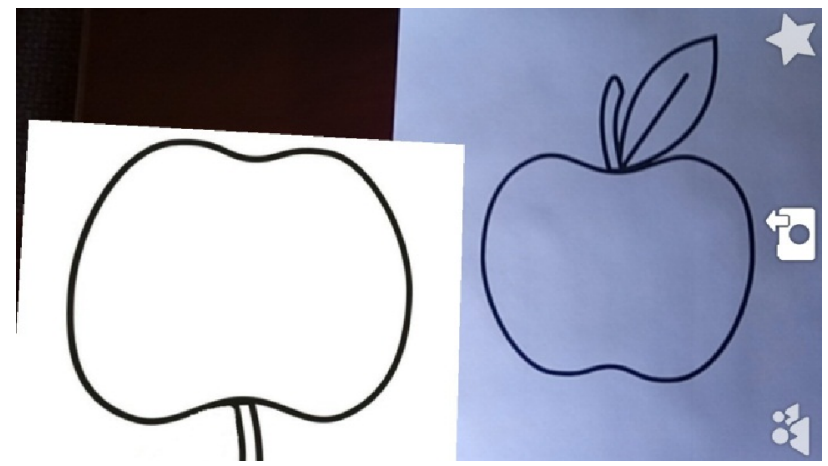

Fig. 3. Screenshot of Task 5

The second group of tasks included teaching children to understand the meaning of words and their correlation with images, as well as the sequence of actions of the plot image.

1. Understanding of the antonyms and synonyms: sweet - bitter, big - small, wide narrow, long - short; "What can stand?"; "What can be called a leg?"; "What can be: cold, bitter, heavy, and useful?".

2. Finding and showing the ruler by a pointer, showing a pointer by a ruler; showing a pencil by a pointer, showing a pointer by a pencil.

3. Understanding of the sentences of the convertible design: Show where on the picture: "Sasha makes the feeder. Feeder is made by Sasha". "A girl reads a book. The book is read by the girl".

4. Understanding the images of a series of pictures and locating them according to the plot content.

5. Correlation of the subject's image on the picture and its graphic representation on the icon.

6. Correlation of the object and its image. Selection of pairs (Fig. 4).

The third group of tasks required the children to execute movements and to repeat the phrases according to the model of the teacher in a certain sequence:

1. Imitation of the teacher's model of the kinetic melody with the successive change of the three positions of the hand: the palm - the fist - an edge. 
2. Making exercises for the fingers of the hands of the teacher's model: the first finger the second finger; the first finger - the third finger; the first finger - the fourth finger; the first finger - the fifth finger and vice versa.

3. Execution of articulation movements: dynamic and static.

4. Repetition of simultaneously proposed pairs of words, or series of words: cup - table; field - flowers; goat - spit - dew ([koza - kosa - rosa $]$ ); cancer - poppy - the roof ([rak - mak - dakh]).

5. Repetition of the proposed images on two pictures in series in memory: the apple is small - the apple is large; a thin book - a thick book, etc. (Fig. 5).

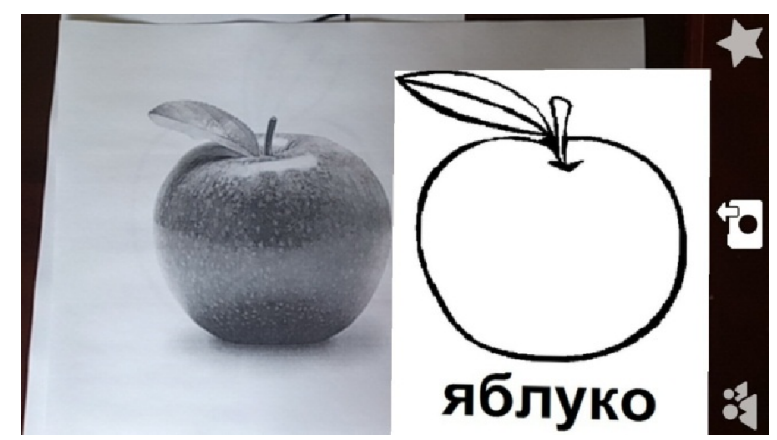

Fig. 4. Screenshot of Task 6

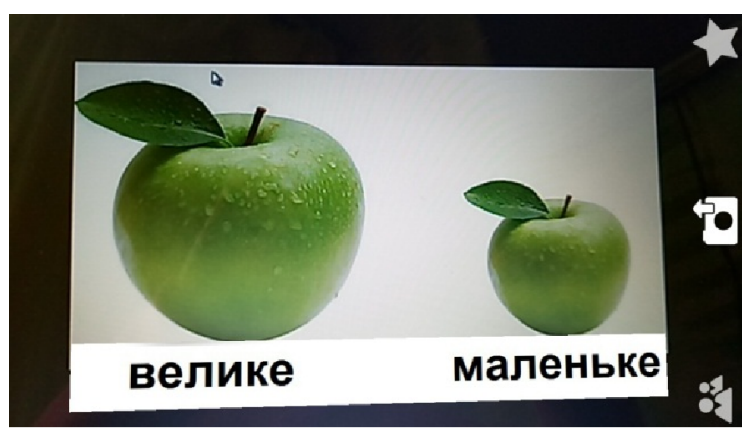

Fig. 5. Screenshot of Task 5

Illustrations (by Inna V. Koroleva, Larisa G. Nurieva) were included in the program of work for autistic children. Cards of transparent material with contours of words and numbers were selected on a game field with icons depicting a certain type of movement or subject matter (Elephant is going, the turtle is creeping, the blue ball is one, two yellow balls).

After the successful formation of regulatory visual movements, vestibular projections, optical and kinesthetic sensations, the development of sensorimotor abilities and successive structures at the mental level, learning for global reading became the next stage in working with autistic children. 
The ability of children with ASD to perceive and memorize the schematic images well, their sequence, allowed us to offer them graphic images of words - the method of global reading. The main purpose of global reading teaching was the tasks of developing of impressive, narrative, free reading. Successful implementation of the assignments of global reading was provided, first of all, by the selection the words and images familiar to children of four years old (vocabulary which found in children during the survey) for reading.

Cards with words of red color (letters in the size from 2 to $5 \mathrm{~cm}$ ) by the Doman method were used previously. Every day a new set of 5 words for reading was offered to children. These were engrams (names of loved ones, the heroes of animated films), words that meant everyday items, parts of the body, and so on.

The tasks were offered in a certain sequence for proper understanding and remembering of images on the card. At first, the child remembered the inscriptions on the cards and learned to pick their pairs. At the next stage, the pupils mastered the ability to recognize and select the inscription on the card (nouns, verbs, adjectives), to match with the sample (Fig. 6).

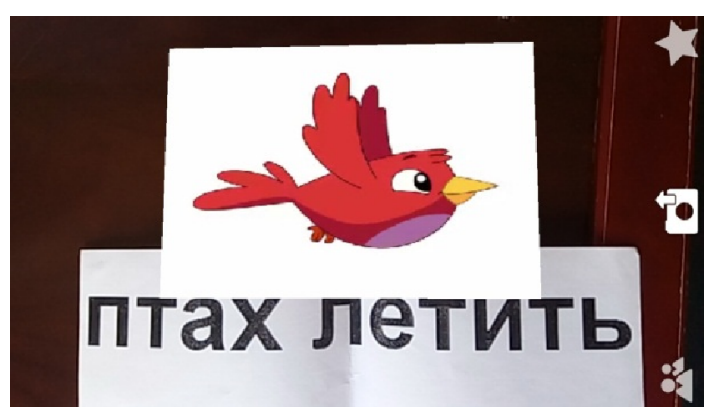

Fig. 6. Screenshot of Task

When learning lexical themes: "Clothes", "Toys", "Food", "Dishes", etc. the teacher laid out the cards with words and called them. The next task required the child to select a card with the corresponding image and its correlation with the word on the card. As a result of the application of such techniques, five-year-old children with ASD quickly mastered the vocabulary of program topics.

By the global method of reading, children quickly and with great interest master the words antonyms (sweet - bitter, high - low, merry - sad) and paronyms (sac - cancer, ([sak - rak]), goat - spit ([koza - kosa])).

Gradually, the tasks were complicated by the transition of reading the phrases, depicted in the pictures (a large ball - a small ball, an empty bucket - a full bucket). The children liked to pick up incompatible, funny, absurd phrases and words-actions to them.

An integral part of this phase was making books illustrated by photographs of children and their loved ones, favorite animals, who performed various actions by children together with parents. Each page of the book was signed by phrases, and later with 
sentences (I am playing, my mother is reading, the dog is asleep, I am eating a watermelon.).

Until the next stage of reading the sentence, for children 6 years the type has decreased to the usual and its color has changed from red to black.

A successful practice in the global reading method of sentences was using of nouns, verbs and colored cards for the recording (nouns on a yellow background, verbs - on a green background).

Quite easily, children fulfilled the teacher's commands using one verb and different nouns ("Show the doll", "Show hands", "Show the table") and pick up the corresponding cards at the same time.

Alternatively, when reading verbs, the cards on which objects were already depicted to compose sentences were used, and the children took the word-action written on the card. Such a task was difficult and therefore uninteresting for children, but using of the augmented reality "animated" the heroes of the picture, allowed not only to show the story, but illustrate the actions of the heroes as in cartoons, which children like (Fig. 7).

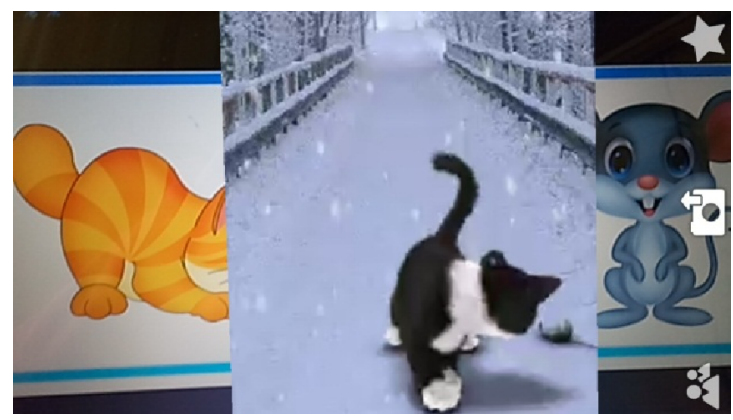

Fig. 7. Screenshot of Task

\section{Conclusions}

The analysis of the two-year experimental work with preschoolers with ASD (middle and senior groups) suggests that the proposed program of teaching global reading was completely taken up by children. Approbation of the methodology of teaching global reading using the augmented reality of preschool children with ASD showed the positive results. The technology of augmented reality allowed combining the real and virtual objects to interact with them in real time. It became possible to enhance the interest and motivation to conscious activity, the formation of new values in the knowledge of the surrounding world. Observation of realistic images stimulated cognitive processes, which led to a qualitatively new level of assimilation and processing of information by autistic children.

Thus, the application of augmented reality technology helped to improve the efficiency of correctional and developmental training for children with special educational needs. 
Prospects for further experimental research will be the implementation of the proposed methodology and obtaining its effectiveness and efficiency in practice.

\section{References}

1. Korsunskaia, B.D.: Chtenie kak tcel i sredstvo v sisteme doshkolnogo obucheniia glukhikh (Reading as a goal and means in the system of preschool education for the deaf). Defektologiia. 1, 39-47 (2007)

2. Kret, Ya., Baikina, N.: Navchannia hlobalnomu chytanniu ditei z diahnozom Kannera (rannim dytiachym autyzmom) i zatrymkoiu movnoho rozvytku (Teaching global reading for children with Kanner's diagnosis (early childhood autism) and lingering developmental delay). Pedahohika, psykholohiia ta medyko-biolohichni problemy fizychnoho vykhovannia i sportu. 4, 76-78 (2006)

3. Martcenkovskii, I. A. (ed.): Ocherki detskoi psikhiatrii. Autizm (Sketches of child psychiatry. Autism). NeuroNEWS (2014)

4. Modlo, E.O., Echkalo, Yu.V., Semerikov, S.O., Tkachuk, V.V.: Vykorystannia tekhnolohii dopovnenoi realnosti u mobilno oriientovanomu seredovyshchi navchannia VNZ (Using technology of augmented reality in a mobile-based learning environment of the higher educational institution). Naukovi zapysky, Seriia: Problemy metodyky fizyko-matematychnoi i tekhnolohichnoi osvity. 11(1), 93-100 (2017)

5. Nurieva, L.G.: Razvitie rechi u autichnykh detei: metodicheskie razrabotki (Development of speech in autistic children: methodological developments). Terevinf, Moscow (2016)

6. Sekerin, V.D., Gorokhova, A.E., Shcherbakov, A.A., Iurkevich, E.V.: Interaktivnaia azbuka s dopolnennoi realnostiu kak forma vovlecheniia detei v obrazovatelnyi protcess (Interactive alphabet with augmented reality as a form of involving of children in the educational process). Otkrytoe obrazovanie. 21(5), 57-61 (2017)

7. Tarasun, V.V.: Preventyvne navchannia doshkilnykiv z porushenniamy movlennievoho rozvytku (Preventive training for preschool children with speech development disorders). Pravda Yaroslavychiv, Kyiv (1998) 